\title{
The challenges of severe acute respiratory syndrome coronavirus 2 (SARS-CoV-2) testing in low-middle income countries and possible cost-effective measures in resource-limited settings
}

\author{
Zamathombeni Duma ${ }^{1,2^{*}}$ (D) Anil A. Chuturgoon ${ }^{3}$, Veron Ramsuran ${ }^{1}$, Vinodh Edward ${ }^{4}$, Pragalathan Naidoo ${ }^{1,2}$,
} Miranda N. Mpaka-Mbatha ${ }^{1,2,5}$, Khethiwe N. Bhengu ${ }^{1,2,5}$, Nomzamo Nembe ${ }^{1,2}$, Roxanne Pillay ${ }^{1,2,5}$,

Ravesh Singh ${ }^{1}$ and Zilungile L. Mkhize-Kwitshana ${ }^{1,2}$

\begin{abstract}
Diagnostic testing for the Severe Acute Respiratory Syndrome Coronavirus 2 (SARS-CoV-2) infection remains a challenge around the world, especially in low-middle-income countries (LMICS) with poor socio-economic backgrounds. From the beginning of the pandemic in December 2019 to August 2021, a total of approximately 3.4 billion tests were performed globally. The majority of these tests were restricted to high income countries. Reagents for diagnostic testing became a premium, LMICs either cannot afford or find manufacturers unwilling to supply them with expensive analytical reagents and equipment. From March to December 2020 obtaining testing kits for SARS-CoV-2 testing was a challenge. As the number of SARS-CoV-2 infection cases increases globally, large-scale testing still remains a challenge in LMICs. The aim of this review paper is to compare the total number and frequencies of SARS-CoV-2 testing in LMICS and high-income countries (HICS) using publicly available data from Worldometer COVID-19, as well as discussing possible interventions and cost-effective measures to increase testing capability in LMICs. In summary, HICs conducted more SARS-CoV-2 testing (USA: 192\%, Australia: 146\%, Switzerland: 124\% and Canada: 113\%) compared to middle-income countries (MICS) (Vietnam: 43\%, South Africa: 29\%, Brazil: 27\% and Venezuela: 12\%) and low-income countries (LICS) (Bangladesh: 6\%, Uganda: 4\% and Nigeria: 1\%). Some of the cost-effective solutions to counteract the aforementioned problems includes using saliva instead of oropharyngeal or nasopharyngeal swabs, sample pooling, and testing high-priority groups to increase the number of mass testing in LMICS.
\end{abstract}

Keywords: SARS-CoV-2, Low-middle-income countries, Diagnostic testing challenges, Cost-effective strategies, Resource-limited settings

\footnotetext{
* Correspondence: zamathombeniduma@gmail.com

'Department of Medical Microbiology, School of Laboratory Medicine \&

Medical Sciences, Howard College, University of KwaZulu-Natal, Glenwood,

Durban 4041, South Africa

${ }^{2}$ Division of Research Capacity Development, South African Medical Research

Council (SAMRC), Tygerberg, Cape Town 7505, South Africa

Full list of author information is available at the end of the article
}

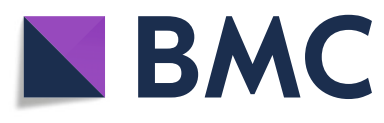

(c) The Author(s). 2022 Open Access This article is licensed under a Creative Commons Attribution 4.0 International License, which permits use, sharing, adaptation, distribution and reproduction in any medium or format, as long as you give appropriate credit to the original author(s) and the source, provide a link to the Creative Commons licence, and indicate if changes were made. The images or other third party material in this article are included in the article's Creative Commons licence, unless indicated otherwise in a credit line to the material. If material is not included in the article's Creative Commons licence and your intended use is not permitted by statutory regulation or exceeds the permitted use, you will need to obtain permission directly from the copyright holder. To view a copy of this licence, visit http://creativecommons.org/licenses/by/4.0/ The Creative Commons Public Domain Dedication waiver (http://creativecommons.org/publicdomain/zero/1.0/) applies to the data made available in this article, unless otherwise stated in a credit line to the data. 


\section{Background}

\section{Overview of SARS-CoV-2}

In December 2019, the World Health Organization (WHO) reported several pneumonia cases in Wuhan, China [1]. Severe Acute Respiratory Syndrome Coronavirus 2 (SARS-CoV-2) was confirmed as the cause of Coronavirus disease 2019 (COVID-19) [2]. Severe Acute Respiratory Syndrome Coronavirus 2 is a positivestranded ribonucleic acid (RNA) virus that primarily infects the upper respiratory tract and is associated with a wide range of complications, including lymphopenia, dyspnea, acute respiratory distress syndrome, pneumonia and acute cardiac arrest [3].

The virus contains four structural proteins namely the spike (S), membrane (M), envelope (E), and nucleocapsid (N) proteins [4]. SARS-CoV-2 entrance into the host cells is mediated by the spike protein. The receptorbinding domain that binds to the peptidase domain of angiotensin-converting enzyme 2 (ACE2) is located at the $S 1$ subunit of the $S$ protein $[4,5]$. The $M$ protein is the virus's most abundant structural protein $[4,6]$ because it interacts with all of the other major coronaviral structural proteins, and it is assumed to be the central coordinator of coronavirus assembly [4]. The E protein is a minor component of the membrane. During the replication cycle, the $\mathrm{E}$ protein is widely expressed inside the infected cell, but only a small portion of it is integrated into the virion membrane $[4,7]$. The nucleocapsid is made up of the viral RNA genome, and the $\mathrm{N}$ protein is the only protein that binds to it. The $\mathrm{N}$ protein is largely involved in viral genome activities, and also plays a role in other aspects of the viral replication cycle as well as the host cellular response to viral infection $[4,8]$.

Countries worldwide have been struggling to contain the highly contagious and rapidly mutating SARS-CoV-2 for more than a year [9]. As of 30 September 2021, the virus has spread to over a hundred countries, and about 222 million coronavirus cases had been confirmed worldwide, resulting in over 4,6 million deaths [10]. The WHO has declared COVID-19 a Public Health Emergency of International Concern $[11,12]$.

\section{Transmission of SARS-CoV-2 and incubation period}

The main mode of transmission of SARS-CoV-2 is by person-person contact [13]. The virus is spread between people through minute aerosol droplets created by sneezing, coughing and talking during close contact. Another way a person can become infected with the virus is by surface transmission [14]. This is because the virus can live on surfaces for up to $96 \mathrm{~h}$ [13]. The virus is more likely to transmit through people who display symptoms early in the disease; this is known as symptomatic transmission [14]. In addition, there is a high chance of passing the virus without showing any signs and symptoms and this is known as an asymptomatic spread [15].

The virus transmission channel, the amount of virus that enters the host, and the interaction between the virus and the host immune system are all factors that influence the incubation period $[16,17]$. According to the $\mathrm{WHO}$ and the Centers for Disease Control and Prevention (CDC), the incubation period for SARS-CoV-2 infection is estimated to be 1-14days, with an average incubation period of around 5-6 days [17, 18]. According to a study conducted in Wuhan, China (January 2020 - February 2020), roughly $97.5 \%$ of SARS-CoV-2 infected patients exhibited clinical symptoms after 11.5 days, and the remaining $2.5 \%$ in 2.2 days [19]. To note, the incubation period varies from person to person [19]. One of the most serious concerns is that SARS-CoV-2 variants have evolved in huge numbers, causing transmission alterations [20]. However, there is limited information about the incubation duration for specific variants [20]. Therefore, more studies are needed to determine whether novel SARS-CoV-2 mutations affect the incubation period. Furthermore, that is the reason why the WHO still emphasizes the recommended quarantine period of 14 days [21].

\section{Safety measures for SARS-CoV-2 infection in LMICs}

According to WHO (2020), the most recommended preventive measures for SARS-CoV-2 infection include social distancing, hand hygiene, using face masks and coughing in the elbow [22]. Implementing the recommended preventive measures in LMICs is a challenge due to unfavorable conditions such as overcrowding in the household, inadequate ventilation in dwellings, ambient and indoor air pollution, lack of clean water supply, refugee settings, the number of persons living on the streets, and poor sanitation [23]. Sanitation is a crucial issue in LMICs because a large number of people, particularly in rural and peri-urban regions, still rely on surface and groundwater sources for their daily water needs [24]. Pit toilets and groundwater are widely used in LMICs, while open defecation near surface water has also been reported as well [25]. The untreated effluent is dumped into the environment, potentially contaminating groundwater and surface resources [26]. As a result, this might partially contribute to the risk of SARS-CoV-2 transmission. Also, to be noted, a few studies reported detecting SARS-CoV-2 in wastewater which has epidemiologic potential and can be used as a backup technique to monitor viral tracking and circulation in places with limited SARS-CoV-2 testing capacity or highly populated regions where door-to-door tracing is difficult. However, in order to improve sensitivity, special 
attention must be paid to virus concentration and detection assays [27].

\section{The consequences of lockdown restrictions in LMICs}

As a way to curb the spread of the rapidly mutating SARS-CoV-2, countries worldwide enforced strict lockdown restrictions [28]. By April 2020, more than 90 countries were in some form of lockdown. Stay-at-home orders, quarantine, isolation, social distancing, curfews, school and company closures, and travel restrictions are all part of the lockdown regulations [29]. The WHO proposed response to the SARS-CoV-2 outbreak involves personal hygiene, effective contact tracing, and isolation when an individual is infected, to strike a balance between lockdown restrictions and normalcy [30]. If implemented in a timely and comprehensive manner, lockdown can be an effective infection control and prevention mechanism, reducing the risk of virus transmission from person to person and population spread while buying enough time to scale up preventative measures, diagnostic tests, and treatment capability [31]. While the rigorous restrictions associated with lockdowns are effective, they come at a cost: they impose significant social and economic constraints on individuals and groups, particularly in LMICs [31].

Workers in the informal economy are affected the most by the lockdown because they lack social security and access to adequate health care, as well as having lost access to productive assets [32]. Hence, without the means to earn an income during lockdowns, many are unable to feed themselves and their families [33]. Due to border closures, trade barriers, and other restrictions, farmers are unable to access markets, causing a disruption in domestic and international food supply chains as well as limiting access to balanced, healthy, and diverse meals [34]. Therefore, millions of women, children and men's food security have been compromised as a result of breadwinners losing their jobs due to the lockdown in low-income countries, with vulnerable communities such as small-scale farmers and indigenous people being the hardest hit [34].

Attempting to strengthen the economy of several LMICs, various governments have opted to ease lockdown restrictions. Therefore, lockdown restrictions in various countries were relaxed at various periods [35]. Currently, governments throughout the world are struggling to figure out whether and how to relax restrictions while balancing numerous health, social, and economic issues. Premature lifting of lockdown restrictions by allowing businesses to operate, opening schools and higher education institutions, and allowing traveling are among the key factors contributing to the resurgence of SARS-CoV-2 waves [36]. Hence, LMICs should try to learn from previous waves of SARS-CoV-2 infection and try to avoid being caught off guard by more waves of SARS-CoV-2 infection in the future [36]. This means it is crucial to develop methods that are cheaper, simple, and have a quick diagnostic turnaround time to avoid the medical laboratory staff becoming overwhelmed during the future waves.

\section{Challenges of SARS-CoV-2 testing in LMICs}

Mass testing is one of the most significant aspects of lowering the SARS-CoV-2 infection rate through early detection of cases for treatment and subsequent cautionary measures such as isolation to prevent death and further virus transmission, respectively [37]. However, identification and monitoring of the SARS-CoV-2 infection cases have been the greatest challenge in the LMICs [37]. In LMICs, SARS-CoV-2 infection testing is problematic due to financial constraints and other factors [38]. These countries have no domestic capacity to manufacture nasopharyngeal swabs, analytical reagents and COVID 19 kits for SARS-CoV-2 testing [39]. With an increase in the number of SARS-CoV-2 infection cases, mass testing becomes disrupted due to a shortage of nasopharyngeal swabs, analytical reagents and COVID 19 kits. It is because buying all of the materials needed to test for SARS-CoV-2 infection is excessively expensive [40]. Furthermore, the cost of Personal Protective Equipment (PPE) has increased since the SARS-CoV-2 outbreak started, with LMICs bearing the brunt of the burden. The prices of surgical masks have increased sixfold, N95 breathing masks have tripled, and gowns have doubled. The problem is supply delivery could take months, and market manipulation is common, with inventories being sold to the highest bidder. This is concerning since healthcare workers rely on personal protective equipment to safeguard themselves and their patients from SARS-CoV-2 infections and the spread of infections. Therefore, doctors, nurses, and other frontline workers in LMICs are severely underequipped to care for SARS-CoV-2 patients because of limited access to equipment including gloves, medical masks, respirators, goggles, face shields, gowns, and aprons [41]. In addition, there are fewer laboratory staff trained for SARS-CoV-2 testing in LMICs. As the number of infection cases increases the laboratory staff becomes overwhelmed, and as a result, diagnostic turnaround time and transmission rates will be increased [40, 41].

Obtaining the best effective vaccine program and uneven access to vaccine programs are two other important concerns in LMICs. Vaccine distribution in the world remains highly unequal, with a majority of the existing supply going to high-income countries (HICs) [42]. Hence, it will take months to years for the COVID19 vaccine to have an impact against the SARS-CoV-2 in LMICs. As a result, this is concerning because the 
vaccine program was supposed to be the way out of this crisis [43]. In 2021, millions of people in LMICs would be denied access to the COVID-19 vaccine due to wide disparities in COVID-19 vaccine access between HICs and LMICs [43]. As a consequence, the outbreak may be prolonged, increasing the risk of additional mutation and reducing the efficacy of current vaccines. Therefore, LMICs need to come up with innovative approaches to fight this contagious virus [20].

The major concern is how will LMICs deal with the SARS-CoV-2 pandemic? As a result, using publicly available data from Worldometer COVID-19 [10], this review paper will compare the total number and frequencies of SARS-CoV-2 testing in LMICs and HICs, as well as discussing possible interventions and cost-effective measures to increase testing capability in LMICs.

\section{Literature review and data sourcing}

Article search strategies, inclusion and exclusion criteria and data sourcing for the study is presented in the Prisma flow diagram (Fig. 1).

\section{Results and overall findings}

Table 1, Figs. 2 and 3 provide a comparison of the total number and frequencies of SARS-CoV-2 testing in each income group (low, middle, and high) and continent. The data in Table 1, Figs. 2 and 3 shows that highincome countries have undertaken 10 times more SARSCoV-2 testing compared to LMICs [10]. More than $100 \%$ of the population in HIC (USA: 192\%, Australia: 146\%, Switzerland: $124 \%$ and Canada: $113 \%$ ) has been tested for SARS-CoV-2, whereas only $27,5 \%$ of the population in middle-income countries (MIC) (Vietnam: 43\%, South Africa: 29\%, Brazil: 27\% and Venezuela: $12 \%$ ) and approximately $3 \%$ of the population in low-income countries (LIC) (Bangladesh: 6\%, Uganda: 4\% and Nigeria: 1\%) has been tested.

The possible reasons for under-testing for SARS-CoV2 infection in LMICs are probably many people are unable to afford SARS-CoV-2 testing due to financial restrictions, unstable health systems and reliance on global supply chains. As a result, many positive cases are simply missed, putting LMICs at higher risk of spreading the virus [31]. The pandemic will easily shatter the poor health system and overburden hospitals and clinical services if effective prevention is not implemented [45].

\section{Possible cost-effective strategies to increase testing capability in LMICs}

The management of SARS-CoV-2 infection cases entails early detection of the virus and prompt isolation as a result, which will aid in the prevention and control of virus spread [46]. Using cost-effective approaches such as saliva instead of oropharyngeal or nasopharyngeal swabs, sample pooling, testing high-priority groups and using antigen rapid tests can help to increase the number of mass testing in LMICs.

\section{Saliva sample for SARS-CoV-2 infection testing}

The recommended sample type for SARS-CoV-2 detection is nasopharyngeal and/ or oropharyngeal swabs [47]. The problem with nasopharyngeal and oropharyngeal swabs is that it makes patients uncomfortable, forcing them to cough during sample collection and

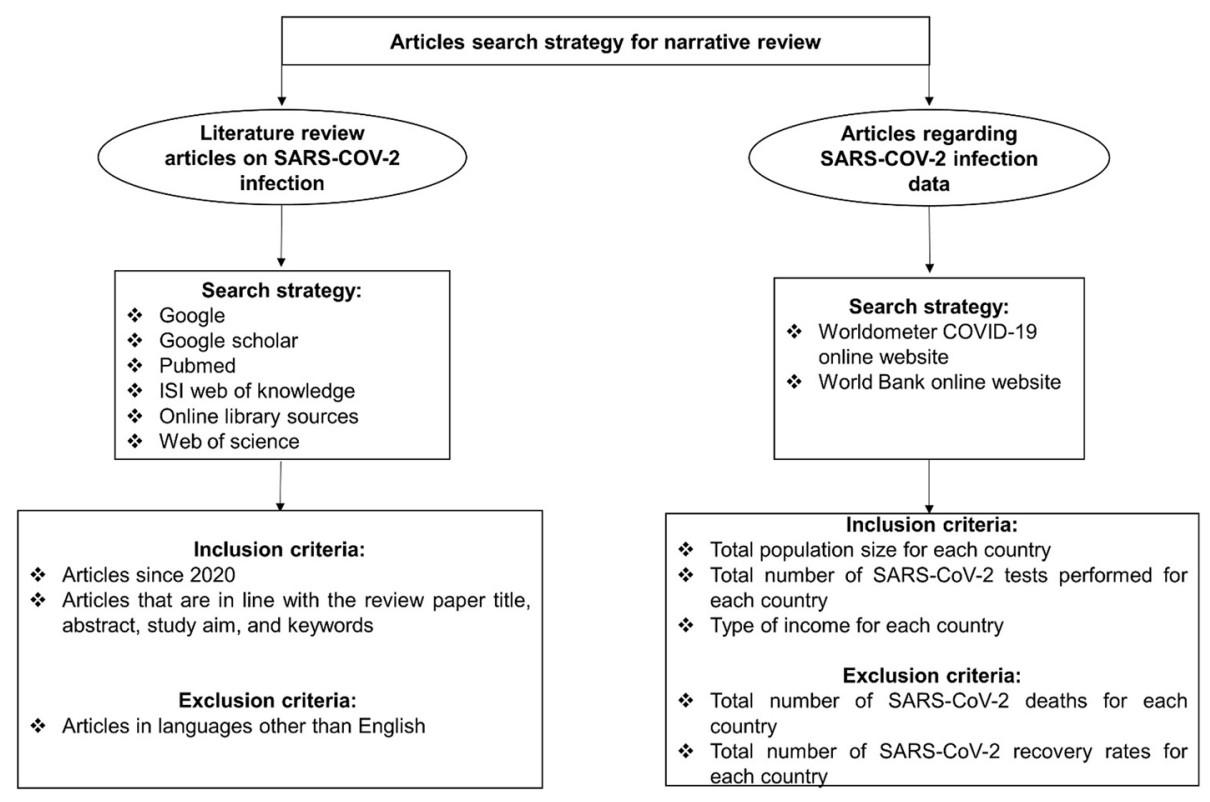

Fig. 1 Prisma flow chart for SARS-CoV-2 literature articles and data search strategies 
Table 1 Comparison between the total number of tests (in million) performed and the total population (in million) in high-income countries and LMICS

\begin{tabular}{llllll}
\hline Continent & Countries & Income & Total Tests Performed (million) & Total Population (million) & Percentage of Tests performed (\%) \\
\hline North America & USA & High & $639,832,856$ & $333,416,037$ & $192^{1}$ \\
Oceania & Australia & High & $37,832,547$ & $25,854,460$ & $146^{1}$ \\
Europe & Switzerland & High & $10,796,404$ & $8,733,303$ & $124^{1}$ \\
North America & Canada & High & $43,215,201$ & $38,153,447$ & $113^{1}$ \\
Europe & Germany & High & $73,348,901$ & $84,117,156$ & 75 \\
Asia & Vietnam & Middle & $42,517,091$ & $98,427,082$ & 43 \\
Africa & South Africa & Middle & $17,649,727$ & $60,237,549$ & 29 \\
South America & Brazil & Middle & $57,282,520$ & $214,437,809$ & 27 \\
South America & Venezuela & Middle & $3,359,014$ & $28,335,663$ & 12 \\
Asia & Bangladesh & Low & $9,704,722$ & $166,728,314$ & 6 \\
Africa & Uganda & Low & $1,680,863$ & $47,529,564$ & 4 \\
Africa & Nigeria & Low & $2,997,060$ & $212,473,029$ & 1 \\
\hline
\end{tabular}

Data were retrieved from the Worldometer Covid 19 on 30 September 2021 [10]. \% Tests performed=(Total Tests/Total Population) * 100). The data on various types of income for each country was obtained from the World Bank online site [44]. ${ }^{(1)}$ Excessive SARS-CoV-2 testing is indicated by percentage values above 100 (SARS-CoV-2 tests performed more than the actual population)

exposing health care workers to the high risk of infection. Furthermore, nasopharyngeal and oropharyngeal swabs are expensive because the sample has to be collected by trained health care personnel wearing PPE [48]. Therefore, the nasopharyngeal and oropharyngeal swab is not an ideal sample to utilize for monitoring SARS-CoV-2 load. Therefore, saliva could be used as an alternative sample for SARS-CoV-2 testing and viral load monitoring, due to its numerous advantages [49].

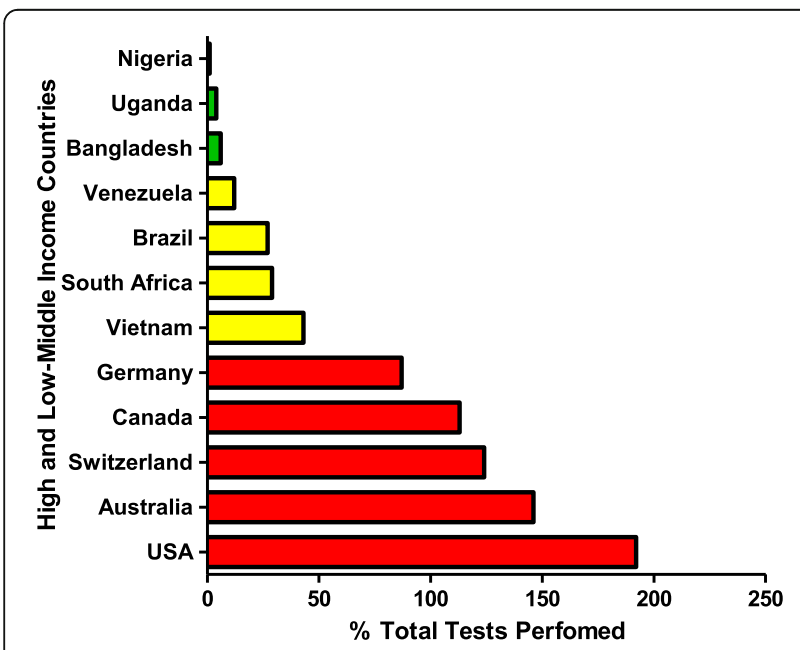

Fig. 2 The number of SARS-CoV-2 tests (\%) performed in highincome and middle-low-income countries and these samples represents counties of each income group. High-income countries are highlighted in red, middle-income countries are highlighted in yellow, and low-income countries are highlighted in green [10]. High-income countries (USA, Switzerland, Australia, Canada, Germany). Middle-income countries (Venezuela, Vietnam, South Africa, Brazil). Low-income countries (Bangladesh, Uganda, Nigeria)
Saliva is a transparent biofluid generated by the salivary glands that clean and protects the oral cavity, has antibacterial properties, and aids in food digestion [50]. Angiotensin-converting enzyme 2 (ACE-2) has been identified as the principal host cell receptor of SARS$\mathrm{CoV}-2$, and it is thought to play a key role in the virus's entry into the cell and subsequent infection. The ACE-2 receptor is highly expressed in the salivary gland and oral mucosa, [51] ACE2-positive cells in the salivary glands are likely to be SARS-CoV-2 target cells [52] Furthermore, the presence of SARS-CoV-2 in saliva could be due to the mixing of upper and lower respiratory tract fluid that conveys the virus to the saliva. These findings imply that the salivary gland and oral mucosa could be a high-risk source site for SARS-CoV-2 infection [52]. Hence, this is what makes saliva a suitable specimen for testing SARS-CoV-2 infection.

Saliva could be utilized as a diagnostic sample for detecting SARS-CoV-2 and monitoring viral load [53]. Patients collect their own samples, which has several benefits, including the elimination of health care staff and the elimination of PPE for sample collection. The time, cost, and risk of viral transmission associated with sample collection are reduced, allowing for increased SARS-CoV-2 mass testing [53, 54]. Furthermore, saliva can be utilized efficiently in large organizations such as universities since PPE is not required, and this could help to lower the danger of viral transmission. Hence, the addition of saliva testing for SARS-Cov-2 infection will allow universities to test thousands of students and staff, with the aim that the results will aid in keeping campuses safe. As a result, saliva testing, in addition to wearing a face mask and maintaining social distance, is an innovative option [55]. However, less attention has 


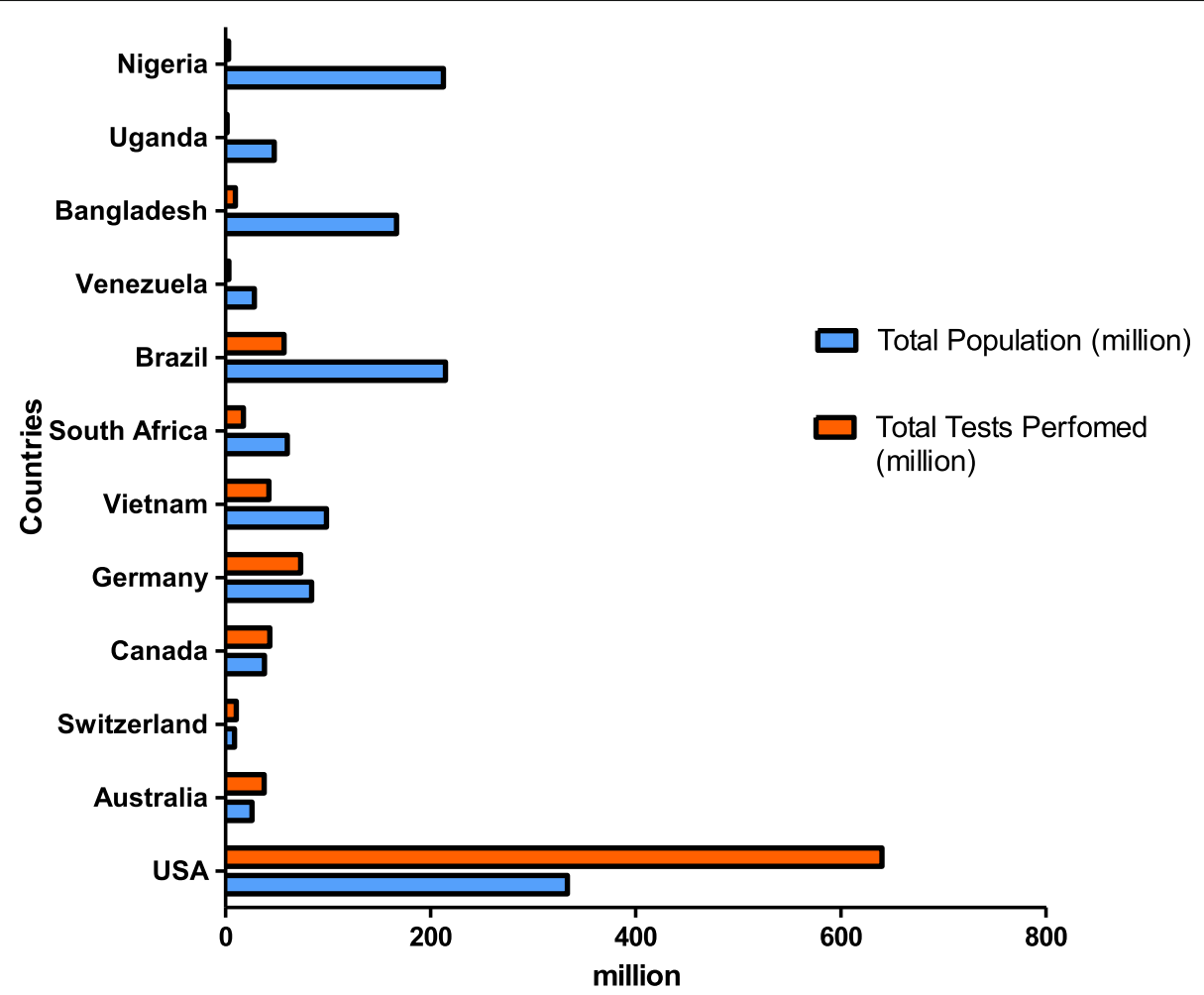

Fig. 3 Comparison between the total population size (million) and the total number of SARS-CoV-2 tests performed (million) in each country [10]. High-income countries (USA, Switzerland, Australia, Canada, Germany). Middle-income countries (Venezuela, Vietnam, South Africa, Brazil). Lowincome countries (Bangladesh, Uganda, Nigeria)

been given to its potential usefulness in testing and monitoring for SARS-CoV-2 infection [54].

\section{Sample pooling}

The gold standard for diagnosing SARS-CoV-2 infection is reverse-transcription polymerase chain reaction (RTPCR), a molecular method [56]. Real-time PCR is precise, but it is expensive to test each individual regularly [57]. Therefore, high prices limit affordability for many people, particularly in LMICs. The cost savings can be achieved by pooling samples $[57,58]$.

The principle of sample pooling allows multiple samples to be mixed and tested as a single sample [59]. When using a pooling method and the pooled test result is negative, each batch component is treated as if it were analyzed separately. Individual testing is required only when the pool test results are positive [59]. Sample pooling testing should be recommended for asymptomatic suspected cases, excluding those who are symptomatic [60]. This method is advantageous because it is costeffective and allows for increased mass testing for SARSCoV-2 without compromising testing accuracy or wasting consumables such as analytical reagents and extraction kits [61]. As a consequence, this technique improves testing efficiency by reducing the backlog of
SARS-CoV-2 pending tests while also enhancing diagnostic turnaround time, which is one of the most important elements in managing and controlling the SARS-CoV-2 outbreak [62]. The pooling technique will be extremely advantageous in a laboratory with limited resources because this type of testing is more feasible and less expensive for mass screening in a large community [63].

\section{Prioritized groups for testing of SARS-CoV-2 infection}

It is critical to have a quick and accurate strategy for detecting and controlling SARS-CoV-2 outbreaks in communities and hospitals in LMICs [64]. In LMICs, prioritizing certain individuals for testing of SARS-CoV2 infection should be considered. This testing strategy will help to accommodate the countries with limited resources by prioritizing individuals according to their categories of urgent clinical need while trying to reduce a backlog of pending testing [65]. Testing becomes the highest priority when it contributes to improving clinical outcomes and decreasing the transmission rate of the virus [66].

When prioritizing groups, the most important factors to consider are the size of each group, the number of tests needed, and the number of tests available. Hence, 
the most critical groups should be tested first. As testing becomes more generally available, it should be gradually spread to other groups based on their priorities. Additionally, those who tested positive for SARS-CoV-2 infection will need to undergo further testing [65].

A list of priority groups for SARS-CoV-2 testing in the private and public sectors is as follows: (i) Symptomatic patients, regardless of their age or underlying health issues, should be given the highest priority to reduce the risk of nosocomial transmission and protect health care staff and the general public. (ii) People who had contact with people who had tested positive for SARS-CoV-2 infection, whether asymptomatic or symptomatic, in order to quickly identify patients at high risk of complications and ensuring that the required precautions are taken. (iii) SARS-CoV-2 testing should also be prioritized for healthcare workers, frontline responders, essential critical infrastructure workers, miners, travelers, people going for surgery, testing pregnant women who are admitted at the labor ward and post-mortem testing, regardless of whether they are asymptomatic, to prevent a possible spread in the community and at work. (iv) If resources are available, testing for non-essential workers may be permitted $[67,68]$. The most important thing to note is that healthy people who have not been tested should continue to practice social distance and wearing masks as recommended by their local and state health authorities $[69,70]$.

\section{Antigen rapid test as a screening test for SARS-CoV-2 infection in LMIC}

As the world continues to wrestle with SARS-CoV-2 infections, the number of cases in LMIC are increasing, causing national economies to lock down and putting further strain on already struggling economies [71]. As a result, the antigen rapid test can be used as alternative strategy for SARS-CoV-2 infection in LMIC. Antigen rapid tests have the advantage of providing results in 15-30 min instead of in hours or days, allowing mass testing to be increased, especially in LMICs with limited laboratory facilities or qualified health professionals to do molecular (PCR) tests [72]. The antigen rapid test allows healthcare workers to quickly identify individuals who are infected with SARS-CoV-2, so they be isolated and treated while their contacts are tracked to prevent the virus from spreading to their families and communities. In this case of a SARS-CoV-2 outbreak, where the test turnaround time is crucial, antigen rapid tests play an important role in delivering early results [73].

While governments are increasingly relying on less expensive antigen rapid tests to increase SARS CoV-2 infection testing coverage, however, the test may have low sensitivity [74]. It's critical to confirm an antigen test result with a PCR test, especially if the result of the antigen rapid test contradicts the clinical setting. Therefore, PCR tests remain the gold standard, and their value remains high $[73,75]$. To be noted antigen rapid tests are typically used on symptomatic individuals since they perform best in symptomatic individuals and within a particular number of days of symptom onset [74]. By adopting this alternative strategy for mass testing of SARS-CoV-2 infection, LMICs can spend less money on diagnostics and more money on essential medical equipment for hospitals treating SARS-CoV-2 infected patients, resulting in more lives saved [72].

\section{Conclusion and implication for future research}

In conclusion, as the number of reported cases rises, the pandemic's long-term effect on individuals and

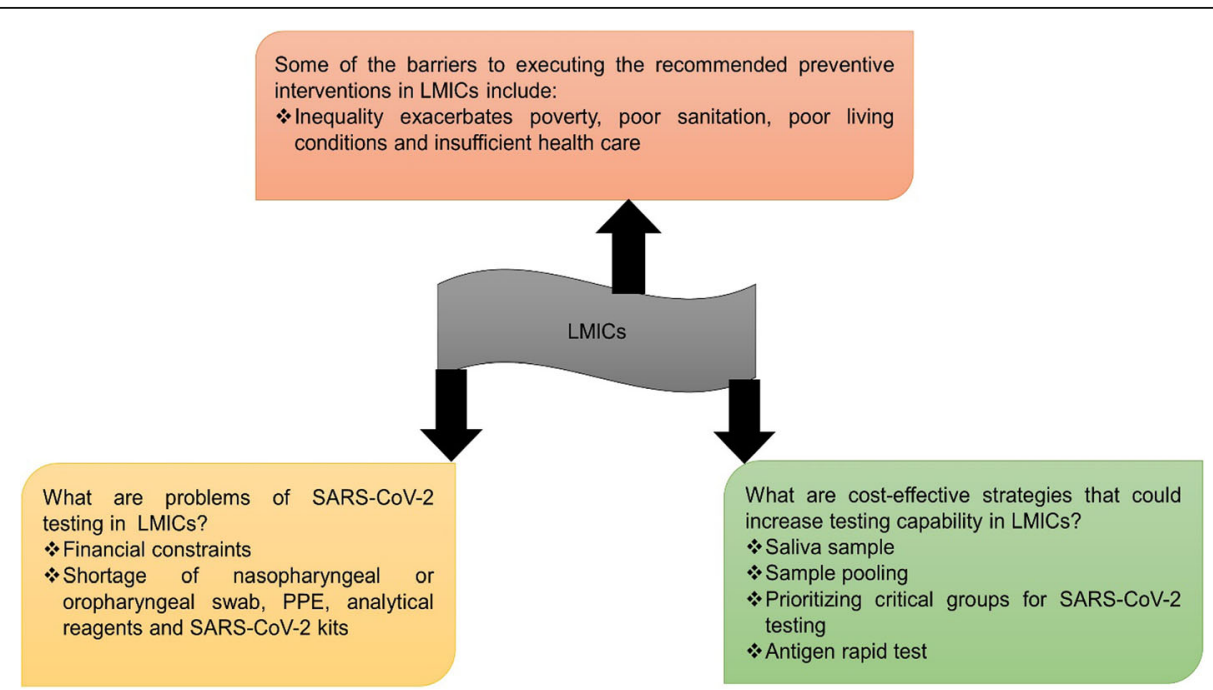

Fig. 4 A summary of the major challenges that LMICs have when it comes to SARS-CoV-2 testing, as well as possible cost-effective strategies for increasing mass testing 
populations in LMICs remains unknown. Moreover, the provision of a specific, effective vaccine to the people in LMICs is still a challenge. With an ongoing, unprecedented outbreak of SARS-CoV-2, the importance of laboratory detection of human coronavirus infections has been emphasized around the world in order to prevent the spread of the infection and properly treat those individuals who have a serious infection. However, due to weak health systems and poverty, LMICs are finding it difficult to manage the SARS-CoV-2 outbreak. This paper highlights the importance of developing alternative strategies for SARS-CoV-2 mass testing that are simple and cost-effective in a resource-constrained setting, and the summary is illustrated in Fig. 4.

For future research, the goal is to evaluate alternative methods that are simple and cheaper, with fast turnaround time and have a high throughput for a resourceconstrained laboratory, so that they can be implemented to facilitate mass testing for SARS-CoV-2 infection in LMICs. Furthermore, such research will have a good impact on the development of a common pricing standard for SARS-CoV-2 kits in LMICs.

\section{Acknowledgements}

We would like to thank South African Medical Research Council (SAMRC) for funding this research.

\section{Authors' contributions}

ZD, AAC, VR and ZLMK have contributed to manuscript conceptualization, review and editing in preparation for submission. ZD wrote the manuscript. VE, PN, MNMM, KNB, NN, RP and RS edited the manuscript in preparation for submission. All the named authors have read and approved the manuscript for submission.

\section{Funding}

Professor ZL Mkhize-Kwitshana was partially supported as a principal investigator (PI) (and researchers ZD, PN, MNMM, KNB, NN and RP) by funding from the South African Medical Research Council (SAMRC) Mid-Career Scientist Programme (MCSP) Grant (SAMRC HDI's award), through its Division of Research Capacity Development under the Research Capacity Development Initiative (RCDI) programme from funding received from the South African National Treasury. The content and findings reported are the sole deduction, view and responsibility of the researchers and do not reflect the official position and sentiments of the SAMRC.

\section{Availability of data and materials}

All the data reported in this review was retrieved from the publicly available original sources.

\section{Declarations}

Ethics approval and consent to participate

Not applicable.

\section{Consent for publication}

Not applicable.

\section{Competing interests}

There are no competing interests declared by the authors.

\section{Author details}

${ }^{1}$ Department of Medical Microbiology, School of Laboratory Medicine \& Medical Sciences, Howard College, University of KwaZulu-Natal, Glenwood, Durban 4041, South Africa. ${ }^{2}$ Division of Research Capacity Development,
South African Medical Research Council (SAMRC), Tygerberg, Cape Town 7505, South Africa. ${ }^{3}$ Department of Medical Biochemistry, School of Laboratory Medicine \& Medical Sciences, Howard College, University of KwaZulu-Natal, Glenwood, Durban 4041, South Africa. ${ }^{4}$ The Aurum Institute, Parktown, Johannesburg 2194, South Africa. ${ }^{5}$ Department of Biomedical Sciences, Mangosuthu University of Technology, Umlazi, Durban 4031, South Africa.

Received: 16 November 2021 Accepted: 3 January 2022

Published online: 22 January 2022

\section{References}

1. Zhu N, Zhang D, Wang W, Li X, Yang B, Song J, et al. A novel coronavirus from patients with pneumonia in China, 2019. N Engl J Med. 2020;38(8): 727-33. https://doi.org/10.1056/NEJMoa2001017.

2. Lake MA. What we know so far: COVID-19 current clinical knowledge and research. Clin Med (Lond). 2020;20(2):124-7. https://doi.org/10.7861/ clinmed.2019-coron

3. Huang C, Wang Y, Li X, Ren L, Zhao J, Hu Y, et al. Clinical features of patients infected with 2019 novel coronavirus in Wuhan. China Lancet. 2020;39(10223):497-506. https://doi.org/10.1016/S0140-6736(20)30183-5.

4. Schoeman D, Fielding BC. Coronavirus envelope protein: current knowledge. Virol J. 2019;16(1):69. https://doi.org/10.1186/s12985-019-1182-0.

5. Siu YL, Teoh KT, Lo J, Chan CM, Kien F, Escriou N, et al. The M, E, and N structural proteins of the severe acute respiratory syndrome coronavirus are required for efficient assembly, trafficking, and release of virus-like particles. J Virol. 2008;82(22):11318-30. https://doi.org/10.1128/JVI.01052-08.

6. Neuman BW, Kiss G, Kunding AH, Bhella D, Baksh MF, Connelly S, et al. A structural analysis of M protein in coronavirus assembly and morphology. J Struct Biol. 2011;174(1):11-22. https://doi.org/10.1016/j.jsb.2010.11.021.

7. Venkatagopalan P, Daskalova SM, Lopez LA, Dolezal KA, Hogue BG. Coronavirus envelope (E) protein remains at the site of assembly. Virology. 2015:478:75-85. https://doi.org/10.1016/j.virol.2015.02.005.

8. de Haan CA, Rottier PJ. Molecular interactions in the assembly of coronaviruses. Adv Virus Res. 2005;64:165-230. https://doi.org/10.1016/ S0065-3527(05)64006-7.

9. Lone SA, Aijaz A. COVID-19 pandemic - an African perspective. Emerg Microbes Infect. 2020;9(1):1300-8. https://doi.org/10.1080/22221751.2020.1 775132 .

10. COVID-19 Coronavirus pandemic. 2020. https://www.worldometers.info/ coronavirus. Accessed 31 Sept 2021

11. Sohrabi C, Alsafi Z, O'Neill N, Khan M, Kerwan A, Al-Jabir A, et al. World Health Organization declares global emergency: a review of the 2019 novel coronavirus (COVID-19). Int J Surg. 2020;76:71-6. https://doi.org/10.1016/j. ijsu.2020.02.034.

12. Osayomi T, Adeleke R, Akpoterai LE, Fatayo OC, Ayanda JT, Moyin-Jesu J, et al. A geographical analysis of the African COVID-19 paradox: putting the poverty-as-a-vaccine hypothesis to the test. Earth Syst Environ. 2021;5(3): 799-810. https://doi.org/10.1007/s41748-021-00234-5.

13. Ong SWX, Tan YK, Chia PY, Lee TH, Ng OT, Wong MSY, et al. Air, surface environmental, and personal protective equipment contamination by severe acute respiratory syndrome coronavirus 2 (SARS-CoV-2) from a symptomatic patient. JAMA. 2020;323(16):1610-2. https://doi.org/10.1001/ja ma.2020.3227.

14. Liu J, Liao X, Qian S, Yuan J, Wang F, Liu Y, et al. Community transmission of severe acute respiratory syndrome coronavirus 2, Shenzhen. China Emerg Infect Dis. 2020;26(6):1320-3. https://doi.org/10.3201/eid2606.200239.

15. Byrne AW, McEvoy D, Collins AB, Hunt K, Casey M, Barber A, et al. Inferred duration of infectious period of SARS-CoV-2: rapid scoping review and analysis of available evidence for asymptomatic and symptomatic COVID-19 cases. BMJ Open. 2020;10(8):e039856. https://doi.org/10.1136/bmjopen-202 0-039856

16. Rai B, Shukla A, Dwivedi LK. Incubation period for COVID-19: a systematic review and meta-analysis. J Public Health (Berl.). 2021. https://doi.org/10.1 007/s10389-021-01478-1.

17. le Polain de Waroux O, Cohuet S, Ndazima D, Kucharski AJ, Juan-Giner A, Flasche $\mathrm{S}$, et al. Characteristics of human encounters and social mixing patterns relevant to infectious diseases spread by close contact: a survey in Southwest Uganda. BMC Infect Dis. 2018;18(1):1-12. https://doi.org/10.1186/ s12879-018-3073-1. 
18. Varia M, Wilson S, Sarwal S, McGeer A, Gournis E, Galanis E, et al. Investigation of a nosocomial outbreak of severe acute respiratory syndrome (SARS) in Toronto. Canada CMAJ. 2003;169(4):285-92.

19. Lauer SA, Grantz KH, Bi Q, Jones FK, Zheng Q, Meredith HR, et al. The incubation period of coronavirus disease 2019 (COVID-19) from publicly reported confirmed cases: estimation and application. Ann Intern Med. 2020;172(9):577-82. https://doi.org/10.7326/M20-0504.

20. Davies NG, Barnard RC, Jarvis Cl, Kucharski AJ, Munday J, Pearson CAB, et al. Estimated Transmissibility and Severity of Novel SARS-CoV-2 Variant of Concern 202012/01 in England. medRxiv. 2020. https://doi.org/10.1101/202 0.12 .24 .20248822 .

21. World Health Organization. 2020. Infection prevention and control during health care when COVID-19 is suspected: interim guidance. https:// wwwwhoint/publications/i/item/10665-331495 Accessed 29 Nov 2020.

22. World Health Organization. 2020. Advice on the use of masks in the context of COVID-19: interim guidance 6 April 2020. https://apps.who.int/iris/handle/ 10665/331693. Accessed 29 Nov 2020

23. Ahmad K, Erqou S, Shah N, Ahmad K, Erqou S, Shah N, et al. Association of poor housing conditions with COVID-19 incidence and mortality across US counties. PLoS One. 2020;15(11):e0241327. https://doi.org/10.1371/journal. pone.0241327.

24. Kookana RS, Drechsel P, Jamwal P, Vanderzalm J. Urbanisation and emerging economies: issues and potential solutions for water and food security. Sci Total Environ. 2020;732:139057. https://doi.org/10.1016/j. scitotenv.2020.139057.

25. Williams M, Kookana RS, Mehta A, Yadav SK, Tailor BL, Maheshwari B. Emerging contaminants in a river receiving untreated wastewater from an Indian urban Centre. Sci Total Environ. 2019;647:1256-65. https://doi.org/1 0.1016/j.scitotenv.2018.08.084.

26. Sunkari ED, Korboe HM, Abu M, Kizildeniz T. Sources and routes of SARS $\mathrm{CoV}-2$ transmission in water systems in Africa: are there any sustainable remedies? Sci Total Environ. 2021;753:142298. https://doi.org/10.1016/j. scitotenv.2020.142298.

27. Sharif S, Ikram A, Khurshid A, Salman M, Mehmood N, Arshad Y, et al. Detection of SARs-CoV-2 in wastewater using the existing environmental surveillance network: a potential supplementary system for monitoring COVID-19 transmission. PLoS One. 2021;16(6):e0249568. https://doi.org/10.13 71/journal.pone.0249568.

28. Sandford, A.2020. Coronavirus: Half of humanity now on lockdown as 90 countries call for confinement. http://www.euronews.com. Accessed 31 Oct 2020

29. Doyle, M. 2020. WHO doctor says lockdowns should not be main coronavirus defence. Https: //www.abc.net.au/ news/ 2020-10-12/ worldhealth-organization-coronavirus-lockdown-advice /2753688. Accessed 14 June 2021.

30. Eyawo O, Viens AM, Ugoji UC. Lockdowns and low- and middle-income countries: building a feasible, effective, and ethical COVID-19 response strategy. Glob Health. 2021;17(1):13. https://doi.org/10.1186/s12992-02100662-y.

31. WIEGO. 2020. Informal Workers in the COVID-19 Crisis. https:// www.wiego org/sites/default/files/resources/file/Informal\%20Workers\%20in\%20the\%2 0COVID-19\%20Crisis.

32. Sinha D. Hunger and food security in the times of Covid-19. J Soc Econ Dev. 2021;23(S2):320-31. https://doi.org/10.1007/s40847-020-00124-y.

33. United Nations. 2020. COVID 19 and Indigenous Peoples Resilience. https:// www.un.org/en/observances/indigenous-day. Accessed 08 June 2021.

34. Giles C, Mwai P. 2020. Coronavirus: Coronavirus: Infections rising amid economic downturn in Africa. https://www.bbc.com/news/world-africa-523 95976. Accessed 26 Nov 2021.

35. Han E, Tan MMJ, Turk E, Sridhar D, Leung GM, Shibuya K, et al. Lessons learnt from easing COVID-19 restrictions: an analysis of countries and regions in Asia Pacific and Europe. Lancet. 2020;396(10261):1525-34. https:// doi.org/10.1016/S0140-6736(20)32007-9.

36. Lopes-Júnior LC, Bomfim E, Silveira DSCD, Olson K, Neves ET, Nunes MDR, et al. Effectiveness of mass testing for control of COVID-19: a systematic review protocol. BMJ. 2020;10(8):e040413. https://doi.org/10.1136/ bmjopen-2020-040413.

37. Bong CL, Brasher C, Chikumba E, McDougall R, Mellin-Olsen J, Enright A, et al. The COVID-19 pandemic: effects on low- and middle-income countries. Anesth Analg. 2020;131(1):86-92. https://doi.org/10.1213/ANE. 0000000000004846
38. Donia A, Hassan S-u, Zhang X, Al-Madboly L, Bokhari H, et al. COVID-19 Crisis Creates Opportunity towards Global Monitoring \& Surveillance. Pathogens. 2021;10:256.

39. Desmet T, Paepe P, Boelens J, Coorevits L, Padalko E, Vandendriessche S, et al. Combined oropharyngeal/nasal swab is equivalent to nasopharyngeal sampling for SARS-CoV-2 diagnostic PCR. BMC Microbiol. 2021;21(1):31. https://doi.org/10.1186/s12866-021-02087-4.

40. World Health Organization. 2020. Shortage of personal protective equipment endangering health workers worldwide. https://www.who.int/ news/item/03-03-2020-shortage-of-personal-protective-equipment-enda ngering-health-workers-worldwide. Accessed 04 Sept 2021

41. VOA. 2020. African Nations Try to Overcome Shortage of COVID-19 Test Kits. https://www.voanews.com/africa/african-nations-try-overcome-shortagecovid-19-test-kits. Accessed 06 Jan 2021

42. Crager SE. Improving global access to new vaccines: intellectual property, technology transfer, and regulatory pathways. Am J Public Health. 2018; 108(S6):414-20. https://doi.org/10.2105/AJPH.2014.302236r.

43. Khamsi R. If a coronavirus vaccine arrives, can the world make enough? Nature. 2020;580(7805):578-80. https://doi.org/10.1038/d41586-020-01063-8.

44. The World Bank. 2021. World Bank Country and Lending Groups. https://da tahelpdesk.worldbank.org/knowledgebase/articles/906519-world-bankcountry-and-lending-groups. Accessed 09 Sept 2021.

45. Pulia MS, O'Brien TP, Hou PC, Schuman A, Sambursky R. Multi-tiered screening and diagnosis strategy for COVID-19: a model for sustainable testing capacity in response to pandemic. Ann Med. 2020;52(5):1-8. https:// doi.org/10.1080/07853890.2020.1763449.

46. World Health Organization. 2020. Clinical management of COVID-19 (Interim Guidance). https://www.who.int/publications-detail/clinical-management-ofcovid-19. Accessed 22 Mar 2021.

47. Patel MR, Carroll D, Ussery E, Whitham H, Elkins CA, Noble-Wang J, et al. Performance of oropharyngeal swab testing compared with nasopharyngeal swab testing for diagnosis of coronavirus disease 2019United States, January 2020-February. Clin Infect Dis. 2021;72(3):403-10. https://doi.org/10.1093/cid/ciaa759.

48. To KKW, Yip CCY, Lai CYW, Wong CKH, Ho DTY, Pang PKP, et al. Saliva as a diagnostic specimen for testing respiratory virus by a point-of-care molecular assay: a diagnostic validity study. Clin Microbiol Infect. 2019;25(3): 372-8. https://doi.org/10.1016/j.cmi.2018.06.009.

49. Medeiros da Silva RC, Nogueira Marinho LC, de Araújo Silva DN, Costa de Lima K, Pirih FQ, Luz de Aquino Martins AR. Saliva as a possible tool for the SARS-CoV-2 detection: A review. Travel Med Infect Dis. 2020;38:101920.

50. Amerongen AV, Veerman EC. Saliva: the defender of the oral cavity. Oral Dis. 2020;8:2-22.

51. Xu H, Zhong L, Deng J, Peng J, Dan H, Zeng X, et al. High expression of ACE2 receptor of 2019-nCoV on the epithelial cells of oral mucosa. Int J Oral Sci. 2020;12(1):8. https://doi.org/10.1038/s41368-020-0074-X.

52. Liu L, Wei Q, Alvarez X, Wang H, Du Y, Zhu H, et al. Epithelial cells lining salivary gland ducts are early target cells of severe acute respiratory syndrome coronavirus infection in the upper respiratory tracts of rhesus macaques. J Virol. 2011;85(8):4025-30. https://doi.org/1 0.1128/JVI.02292-10.

53. Ceron JJ, Lamy E, Martinez-Subiela S, Lopez-Jornet P, Silva FCE, Eckersall PD, et al. Use of saliva for diagnosis and monitoring the SARS-CoV-2: a general perspective. J Clin Med. 2020;9(5):1491. https://doi.org/10.3390/jcm9051491.

54. Fernandes LL, Pacheco VB, Borges L, Athwal HK, de Paula EF, Bezinelli L, et al. Saliva in the diagnosis of COVID-19: a review and new research directions. J Dent Res. 2020;99(13):1435-43. https://doi.org/10.1177/0022034 520960070.

55. Mark Peplow. 2020. Saliva tests show promise for widespread COVID-19 surveillance at universities and workplaces. https://cen.acs.org/analyticalchemistry/diagnostics/Saliva-tests-show-promise-widespread/98/web/2020. Accessed 16 July 2021.

56. Singh A, Shaikh A, Singh R, Singh AK. COVID-19: from bench to bed side. Diabetes Metab Syndr. 2020;14(4):277-81. https://doi.org/10.1016/j.dsx.2020. 04.011.

57. Ramdas K, Darzi A, Jain S. Test, re-test, re-test': using inaccurate tests to greatly increase the accuracy of COVID-19 testing. Nat Med. 2020;26(6):8101. https://doi.org/10.1038/s41591-020-0891-7.

58. Afzal A. Molecular diagnostic technologies for COVID-19: limitations and challenges. J Adv Res. 2020:26:149-59. https://doi.org/10.1016/j.jare.2020. 08.002. 
59. Lagopati N, Tsioli P, Mourkioti I, Polyzou A, Papaspyropoulos A, Zafiropoulos A, et al. Sample pooling strategies for SARS-CoV-2 detection. J Virol Methods. 2021;289:114044. https://doi.org/10.1016/j.jviromet.2020.114044.

60. Ghosh S, Agarwal R, Rehan MA, Pathak S, Agrawal P, Gupta Y, et al. 2020. A compressed sensing approach to group-testing for COVID-19 detection. https://arxiv.org/abs/2005.07895. Accessed 03 June 2021.

61. Vogels CBF, Brackney D, Wang J, Kalinich CC, Ott IM, Kudo E, et al. Saliva Direct: simple and sensitive molecular diagnostic test for SARS-CoV-2 surveillance. medRxiv. 2020;(3):263-280.e6. https://doi.org/10.1016/j.medj.202 0.12.010.

62. Broder AZ, Kumar RA. 2020. A note on double pooling tests. https://arxiv. org/abs/2004.01684. Accessed 03 June 2021.

63. Heng BW, Price E, Scarlett J. 2020. Non-adaptive group testing in the linear regime: strong converse and approximate recovery. https://arxiv.org/abs/2 006.01325. Accessed 23 May 2021.

64. Shimizu K, Kondo K, Osugi Y, Negita M, Mase H, Kondo T, et al. Early COVID19 testing is critical to end the pandemic. J Gen and Fam Med. 2021;22(2): 67-9. https://doi.org/10.1002/jgf2.420.

65. Centers for Disease Control and Prevention. Interim Guidance on Management of Coronavirus Disease 2019 (COVID-19) in Correctional and Detention Facilities. https://www.cdc.gov/coronavirus/2019-ncov/ downloads/guidance-correctionaldetention. Accessed 01 June 2021.

66. Murthy S, Gomersall CD, Fowler RA. Care for Critically ill Patients with COVID-19. JAMA. 2020;323(15):1499-500. https://doi.org/10.1001/jama.2020.3 633.

67. Centers for Disease Control and Prevention. 2021. Interim Guidance on Management of Coronavirus Disease 2019 (COVID-19) in Correctional and Detention Facilities. https://www.cdc.gov/coronavirus/2019-ncov/ downloads/guidance-correctionaldetention. Accessed 02 June 2021.

68. Centers for Disease Control and Prevention. 2020. Interim Infection Control Guidance for Public Health Personnel Evaluating Persons Under Investigation (PUIs) and Asymptomatic Close Contacts of Confirmed Cases at Their Home or Non-Home Residential Settings. https://www.cdc.gov/ coronavirus/2019-ncov/php/guidance-evaluating. Accessed 02 June 2021.

69. HHS-COVID-19-testing-guidance. 2021. COVID-19 Testing and Diagnostics Working Group (TDWG). https://www.fsmb.org/siteassets/advocacy/pdf/hhscovid-19-testing-guidance. Accessed 17 Aug 2021.

70. Association of State and Territorial Health Officials (Astho). 2020. COVID-19 Testing Needs to Be Limited to Priority Groups Until Sufficient Testing Supplies and Personal Protective Equipment is Available Nationwide. https://www.astho.org/Press-Room/COVID-19-Testing-Needs-to-Be-Limitedto-Priority-Groups-for-Now/03-20-20. Accessed 17 Aug 2021.

71. OECD. The territorial impact of COVID-19: Managing the crisis across levels of government. Updated 10 November 2020. https:/www.oecd.org/corona virus/policy-responses/the-territorial-impact-of-covid-19-managing-thecrisis-across-levels-of-government-d3e314e1. Accessed 06 Dec 2021.

72. World Health Organization. 2020. Global partnership to make available 120 million affordable, quality COVID-19 rapid tests for low- and middle-income countries. https://www.who.int/news/item/28-09-2020-global-partnership-tomake-available-120-million-affordable-quality-covid-19-rapid-tests-for-low\%2 D\%2Dand-middle-income-countries. Accessed 06 Dec 2021.

73. Centre Disease Control and Prevention. 2021. Interim Guidance for Antigen Testing for SARS-CoV-2. https:/www.cdc.gov/coronavirus/2019-ncov/lab/ resources/antigen-tests-guidelines.html. Accessed 04 Dec 2021.

74. Dawson L, Kates J. 2021. Rapid home tests for COVID-19: issues with availability and access in the U.S. https:/www.kff.org/coronavirus-covid-19/ issue-brief/rapid-home-tests-for-covid-19-issues-with-availability-and-accessin-the-u-s. Accessed 06 Dec 2021.

75. Mitchell SL, Orris S, Freeman T, Freeman MC, Adam M, Axe M, et al. Performance of SARS-CoV-2 antigen testing in symptomatic and asymptomatic adults: a single-center evaluation. BMC Infect Dis. 2021;21(1): 1071. https://doi.org/10.1186/s12879-021-06716-1.

\section{Publisher's Note}

Springer Nature remains neutral with regard to jurisdictional claims in published maps and institutional affiliations.

\section{Ready to submit your research? Choose BMC and benefit from:}

- fast, convenient online submission

- thorough peer review by experienced researchers in your field

- rapid publication on acceptance

- support for research data, including large and complex data types

- gold Open Access which fosters wider collaboration and increased citations

- maximum visibility for your research: over $100 \mathrm{M}$ website views per year

At BMC, research is always in progress.

Learn more biomedcentral.com/submissions 